\title{
Guided Reflection Model: How Executive Coaching Can Assist Organizational Leaders Enhance Their Creativity, Innovation and Wisdom
}

\author{
Tom Cerni* $^{*}$ \\ Head of Counseling Services, The Scots College, Victoria Road, Bellevue Hill, NSW, Australia \\ *Corresponding author: tom.cerni@sydney.edu.au
}

Received March 29, 2015; Revised April 06, 2015; Accepted April 09, 2015

\begin{abstract}
This paper outlines how executive coaching can assist organizational leaders engage in a guided process of reflection to enhance their creativity, innovation and wisdom. The conceptual model proposed in this paper is an extension of the Cognitive-Experiential Theory (CET; Epstein, 2014) and the recently developed CognitiveExperiential Leadership Model (CELM; Cerni, Curtis \& Colmar, 2015). Empirical research has shown that people are continually influenced by two information processing systems; the rational system, which is a verbal reasoning system, and the experiential system, which automatically learns from experience (Epstein, 2014). The degree of influence varies along a dimension from negligible to almost complete dominance, depending on the context, affect and understanding of self (Denes-Raj \& Epstein, 1994; Epstein, 1998b; Epstein, 2014; Handley, Newstead, \& Wright, 2000). The proposed Guided Reflection Model (GRM) complements the CELM by suggesting that the executive coach can play an integral role in guiding the leader to better understand how the integration of the context, affect and self, that is continually under the influence of the rational and experiential systems, can enhance creativity, innovation and wisdom.
\end{abstract}

Keywords: executive coaching, guided reflection, leadership, information-processing, rational, experiential, creativity, innovation, wisdom

Cite This Article: Tom Cerni, "Guided Reflection Model: How Executive Coaching Can Assist Organizational Leaders Enhance Their Creativity, Innovation and Wisdom.” American Journal of Educational Research, vol. 3, no. 4 (2015): 495-504. doi: 10.12691/education-3-4-17.

\section{Introduction}

In order to maintain the competitive edge organizations need to be adaptive, creative and innovative (Fullan, 2001; Ruef, 2002; Robinson, 2011), however with high expectations and time constraints organisational leaders struggle to develop creative and innovative ideas through self-reflection. There is a tendency for some leaders to confuse performance reviews and meetings for selfreflection. It is not enough to simply create time for selfreflection as the focus may soon shift to other priorities, such as managing conflict in the workplace (Cerni, Curtis \& Colmar, 2012; Thompson, Grahek, Phillips, \& Fay, 2010), relaxation and family matters. The tendency to focus on other priorities other than the self is natural and could be enhanced by executive coaching that takes the leader through a guided reflection process to develop their creativity, innovation and wisdom.

The purpose of this paper is to provide an outline of the Guided Reflection Model (GRM) and how executive coaching can assist leaders develop their creativity, innovation and wisdom by understanding the influence of the rational system and constructive elements of the experiential systems. More specifically, it is argued that the influence of the context, affect and self, that is under constant influence of the rational and experiential systems (Denes-Raj \& Epstein, 1994; Handley, Newstead, \& Wright, 2000) can enhance creativity, innovation and wisdom. The next section provides an outline of the rational and experiential systems according to the Cognitive-Experiential Theory (CET: Epstein, 2014).

\section{Cognitive-Experiential Theory (CET)}

Since its introduction in 1973 as a "global theory of personality”, CET has undergone considerable development through clinical research, including a recent name change from the Cognitive-Experiential Self-theory (CEST) to Cognitive-Experiential Theory (CET; Epstein, 2014); however, it has only recently been applied to the leadership field (e.g., Cerni, Curtis, \& Colmar, 2008, 2010a, 2010b, 2012; 2014; Curtis \& Lee, 2013; Dubinsky, Yammarino, \& Jolson, 1995; Humphreys \&Zettel, 2002). The development of the Cognitive-Experiential Leadership Model (CELM; Cerni, Curtis \& Colmar, 2015) is the first of its kind to examine the connection between the Cognitive-Experiential Theory (CET; Epstein, 2014) and the Full-Range Leadership Theory (FRLT; Bass, 1985). CELM suggests that combining the rational system 
with the constructive use of the experiential system (Epstein, 2001) results in thinking adaptively. This could then enhance transformational leadership techniques (Cerni, Curtis \& Colmar, 2010a; 2010b), choice of conflict-handling styles (Cerni, Curtis \& Colmar, 2012), choice of influencing tactics (Curtis \& Lee, 2013), and organizational outcomes (Cerni, Curtis \& Colmar, 2014; Theeboom, Beersma \& van Vianen, 2014).

CET assumes that all people, including leaders, process information by two bi-directional, interacting systems; that is, the rational (analytical) and experiential (intuitive) systems. The outcome of this processing is a major determinant of how they feel, interpret events, make decisions, and behave (Epstein, 2014). In this paper reference is made to information-processing systems and styles. Systems are considered to be the cognitive structures and mechanisms by which people process information and styles to be people's relatively stable preferences for processing information in particular ways, such that they may make more or less use of particular systems, or use systems in more or less effective ways.
The measure used to assess individual differences in rational and experiential processing is the RationalExperiential Inventory-Long Form (REI-L; Epstein,Pacini, Denes-Raj, \& Heier, 1996) although more refined measures have been subsequently developed (Norris \& Epstein, 2011). The rational system is considered to be a conscious, deliberative, but slow information-processing system, whereas the experiential system is considered to be a faster information-processing system capable of operating automatically, unconsciously and effortlessly without deliberate intention (Epstein et al., 1996, see Figure 1). As the name experiential implies, this system processes information based on well-learned, rehearsed, and lived experiences. Attempting to explain the influence of the experiential system Bargh and Chartrand (1999) noted that "most of a person's everyday life is determined not by their conscious intentions and deliberate choices but by mental processes that are put into motion by features of the environment and that operate outside of conscious awareness and guidance” (p. 462).

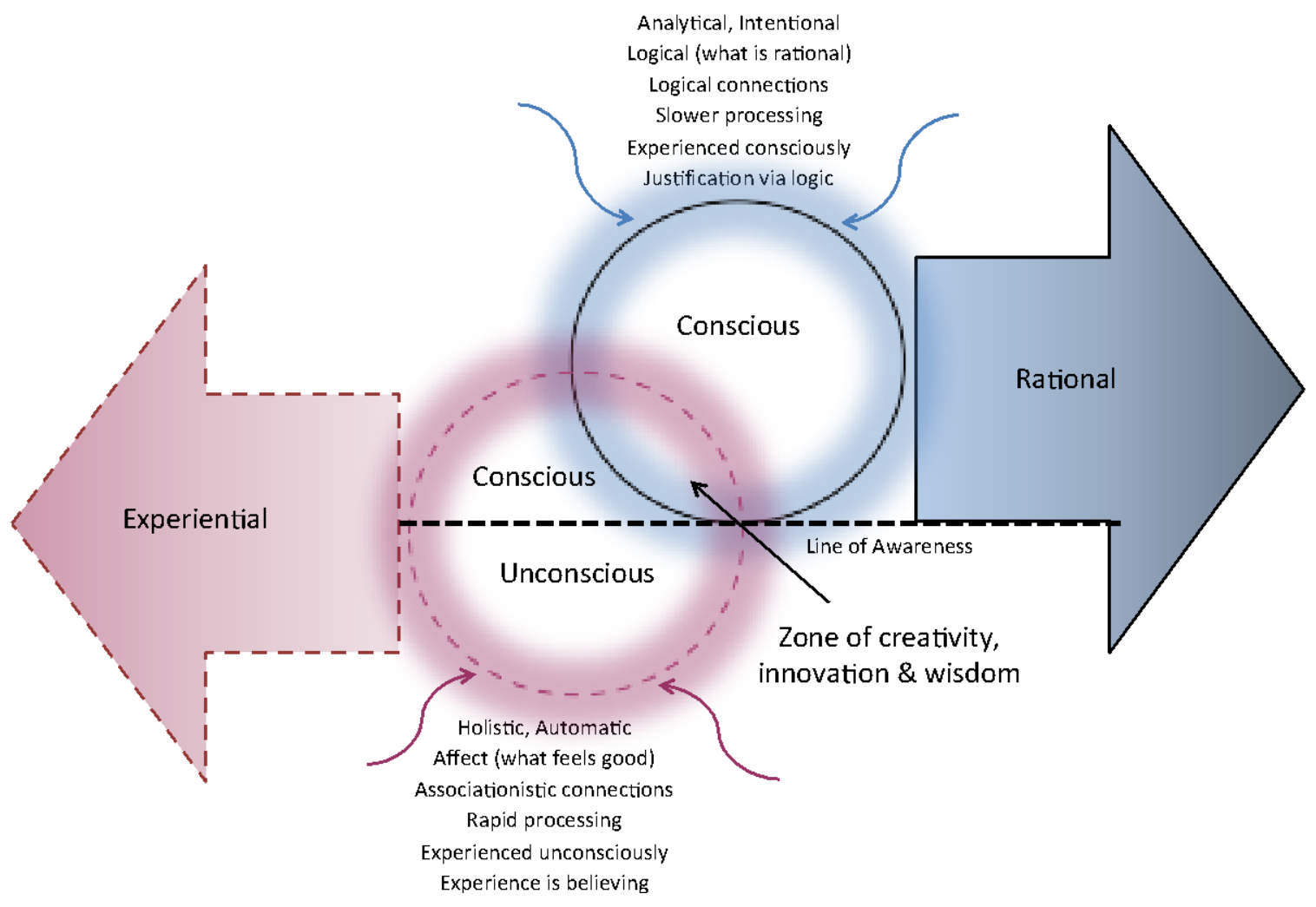

Figure 1. Association between information-processing and levels of awareness

Operating automatically below the line of awareness (see Figure 1), unconscious processing is less demanding of cognitive resources than conscious reasoning (Epstein, 2014). Individual differences in experiential thinking have often been captured by measures of people's preference for thinking intuitively, but individual differences in emotionality and imagination also reflect experiential thinking (Norris \& Epstein, 2011). CET proposes that imagination is an integral component of experiential thinking (Norris \& Epstein, 2011), and in order for leaders to articulate a future vision they must be able to imagine a different future from the past and present.

Although the rational and experiential systems are considered to be relatively independent, it is hypothesized that the overlapping region between the two systems is an enabling region of creativity, innovation, and wisdom (Epstein 1994; Epstein et al., 1996, see Figure 1). Across populations there is no correlation between people's preference for using their rational and experiential thinking systems. Some people prefer to use a great deal of both, while others prefer to use one system in preference to the other (Pacini\& Epstein, 1999). Although individuals may differ in their preference for using these systems, the systems are not independent inasmuch as information that is first learned logically through the rational system may become well-rehearsed over time and accessed automatically from the experiential system. In addition, thoughts that are formed unconsciously through the experiential system may influence what and how information is processed in the rational system. Conscious 
processing can often be biased by unconscious processing making the distinction between conscious and unconscious less meaningful than it would appear (Epstein, 2014).

According to CET each system operates by its own intelligence. The intelligence of the rational system may be captured by traditional measures of general intelligence or cognitive ability. In contrast, the intelligence of the experiential system is captured by individuals' tendency to be constructive thinkers (Epstein \& Meier, 1989). The Constructive Thinking Inventory (CTI; Epstein, 2001) is a measure of individual differences in the efficacy or "intelligence" of the experiential system and people's overall coping ability (Epstein, 2014).

Constructive thinking involves using the experiential system to solve problems in adaptive ways that minimise stress. For example, good constructive thinkers have a tendency to interpret new situations as challenges rather than as threats, and view issues positively but not to an unrealistic degree (Epstein, 2014). The constructive components of the experiential system include: global constructive thinking, emotional coping, and behavioral coping and their respective subscales as operationalized in the Constructive Thinking Inventory (CTI; Epstein, 2001). The destructive components are: personal superstitious thinking, categorical thinking, esoteric thinking, and naïve optimism (Epstein, 2001).

The challenge for present day leaders operating in a world that is changing faster than ever coupled with unprecedented challenges (Robinson, 2011) is to understand how the unconscious experiential system integrates with the conscious rational system to enhance creativity, innovation and wisdom. Although the experiential system is associated with a number of positive (constructive) attributes such as creativity and compassion, it can also be a source of difficulty when it engages in superstitious thinking, prejudice, and biasing the rational system to a point where people are unable to think rationally (Epstein, 2003). Though the experiential system can provide many lessons in life through personal experience it has the potential to elude the articulation and logical analysis of the rational system (Epstein, 2003).

When it comes to creativity, innovation and wisdom it appears that both systems can make an important contribution. The key question is to understand how the rational thinking and the constructive use of experiential thinking could enhance creativity, innovation and wisdom. The initial step involves defining these terms and then linking these to the GRM. Creativity is defined as the process of developing original ideas that have value, and innovation is the process of putting new ideas into practice (Robinson, 2011). In addition to creativity and innovation leaders also require wisdom to provide good judgments, insights and character. They also allow for experiential and subjective elements to enter into their thinking and may appear to have a metaphysical, even spiritual quality that does not bind them to the rational system in order for vision, insight and foresight to emerge (McKenna, Rooney \& Boal, 2009). Sternberg (1988) claims that leadership is wise to the extent that it uses a blend of intelligence, creativity, experience and virtue.

For wisdom to emerge, Webster (2003) suggests that out of the five dimensions including: experience; emotional regulation; reminiscence and reflectiveness; openness; and humour the synthesis of at least two are needed for wisdom to emerge. Ardelt (2003) suggested that only cognitive, reflective, and affective dimensions needed to be present and that the reflective element is considered to be crucial with the affective dimension often overlooked. The next section reviewstypes of selfreflection used in the workplace and how the executive coach can guide the leader beyond self-reflection to enhance their creativity, innovation and wisdom.

\section{Self-reflection in the Workplace}

With billions of dollars spent annually on programs aimed at developing organizational leaders; the effectiveness of leadership programs remains poorly understood (Goldman, Wesner, \&Karnachanomai, 2013). Researchers suggest that there is benefit in developing individual leadership plans at the end of the leadership programs followed by application of experience with subsequent coaching and journal entries cantered around key questions that prompt reflection (Goldman et al., 2013). However, despite the initial high levels of enthusiasm, they fail to adapt the skills in the workplace and slip back into old command-and-control leadership patterns. This is, in part, because ingrained behaviors are difficult to change (Prochaska, Velicier, Rossi, \& Goldstein, 1994).

Self-reflection is considered a central aspect of any organizational work, however it needs to operate from a framework thatassists leaders develop project creativity and innovation by overcoming blind spots and understanding how their behavior may influence the rest of the team (Kegan \& Lahey, 2009; Ollila, 2002). The absence of a self-reflection framework can generate multiple meanings ranging from awareness of thoughts, feelings and actions to imagining alternatives (Mezirow, 1998). In an attempt to narrow the meanings arising from self-reflection, reflection-in-action was developed to assist leaders reflect on what they are doing while they are doing the task. Considered an on-the-spot process it involves surfacing, testing and evaluating intuitive understandings, sometimes not conscious and intrinsic to experience (Schon, 1987).

Self-reflection can be used to evaluate an experience, including the analysis of cause and effect, and then drawing a conclusion about future action (Woerkom, 2003). The outcome of self-reflection can involve the clarification of an issue, the development of a new skill, or the resolution of a problem, however the benefits of selfreflection can be lost if it is not linked back to the action (Gray, 2006). Self-reflection therefore needs to be a continuous process, occurring before, during, and after an action or experience (Clayton \&Ash, 2005). Through selfreflection, people can start to make sense of their experiences, explore their own cognitions and self-beliefs, engage in self-evaluation, and start to alter their thinking and behavior accordingly (Bandura, 1986).

Self-reflection can range from written reflection activities in the form of journals and essays to verbal reflection on a discussion, question, or current events (Harvey \& Jenkins, 2014), however experiential theorists, such as Kolb (1983), believe that people learn more from their experiences when they spend time thinking about 
them (Houghton, Wu, Godwin, Neck, \&Manz, 2012). This suggests that self-reflection needs to be a process of turning experience into learning. It appears however that people who would describe themselves as being comfortable with self-reflection as well as the "doing" process most probably never engaged in a focused, structured, persistent, and actively guided reflection process (Kegan \& Lahey, 2009).

While different forms of self-reflection including: reflection-in-action (Schon, 1987), reflective thinking (Bourner, 2003), critical reflection (Mezirow, 1998)and critical thinking (Leung \&Kember, 2003) can be useful they can only be fully realized through the process of interaction (Woerkom, 2003). It is for this reason that the leader working with an executive coach could enhance the reflection process by initially assessing the values, beliefs and presuppositions based on prior conscious and unconscious learning, and of their consequences (Leung \& Kember, 2003).Following the initial assessment the executive coach can assist the leader move through the structured GRM to explore ways to enhance their creativity, innovation and wisdom.

\section{Executive Coaching and Guided Reflection Model}

Coaching leaders can be a complex process and if done well can mentally improve the leaders' levels of awareness (Ketsde Vries, 2014) by incorporating the right type of experiences that modify old experiential beliefs and biases to accommodate new, more adaptive ones (Epstein, 2014). To achieve these outcomes it is important to develop a systematic, structured and active guided reflection process (Kegan \& Lahey, 2009). Lane and Corrie (2009) suggest that the framework in coaching can be appropriate for the purpose by: (a) assuming a partnership framework which accommodates a variety of stakeholder positions; (b) being inclusive of a broad range of factors, and (c) being applicable to a diverse set of contexts. The GRM appears to incorporate the coaching framework proposed by Lane and Corrie (1989) by assisting the leader to understanding the rational and experiential systems and how these systems can be influenced by the context, affect and understanding of self to enhance creativity, innovation and wisdom.

The art of coaching requires that the executive coach engages the leader to reflect on their day-to-day activities as part of the goal striving process (Vancouver \& Putka, 2000). Coaches implicit beliefs and theories are assumed to be capable of being intentionally transformed by: (a) allowing the personal inner freedom of both coach or coachee to engage in a "two-way flow of influence" (Hollander, 2009), or as Buber (1958) put it, "I-Thou" mutual dialogue; (b) enabling deep personal integration of all 'intra- and inter-personal otherness' to be intentionally brought into existence and (c) shaping the deep reflective space (whether explicitly identified or not) and particular modelling of leadership behavior (Elliott, 2010).

The proposed GRM outlined in this paper consists of three stages: the outer reflective space (Stage 1), inner reflective space (Stage 2), and deep reflective space (Stage 3 ). The overlapping region between the rational and experiential systems is considered to be deep reflective space (see Figure 2). Since the overlapping region operates above the line of awareness the leader is aware that the two systems exist and interact (Epstein, 2014).Most people are aware of the rational system because it operates at the conscious level; however, with the experiential system operating automatically, and at the unconscious level, people may be unaware of its influence (Epstein, 1998a).

The rational and experiential systems have several advantages and disadvantages in how each one influence the other. The advantage of the rational system is that it has the capacity to understand the experiential system when thoughts surface into consciousness; however the experiential system cannot understand the rational system. The advantage of the experiential system is that it can influence the rational system without the rational system being aware of that influence (Epstein, 2006). Perhaps this may explain why some people can solve complex technological problems, yet experience difficulty with emotional regulation and interpersonal skills that are more important to their existence and personal happiness (Hall \& Lord, 1995; Epstein, 2000). It can however be reassuring to know that over time leaders can be taught to understand the operation of the experiential system in general and, even more importantly, to observe its operation in themselves and control its influence. They can also learn to train their experiential system to become better socialized so that there is less need to control it (Epstein, 2014).

For the executive coach to guide the leader towards deep reflection (Stage 3), considered to be the zone of creativity, innovation and wisdom (Epstein 1994; Epstein et al., 1996) the guided reflective process starts with the outer reflective space (Stage 1). This stage consists of the executive coach, context, affect and understanding of the self (see Figure 2).

\section{Stage 1: Outer reflective space}

In Stage 1 the executive coach begins to ask key questions to determine how the context, affect and understanding of self may have contributed to creativity, innovation and wisdom in the past, and how these areas can be developed in the present and future. The next sections outlines the four key factors that make up Stage 1 of the GRM.

Executive coach

A key finding emerging in the broader coaching literature is establishing ahealthy working relationship between the executive coach and leader (Welch, Grossaint, Reid \& Walker, 2014). This is referred to as the "therapeutic alliance" in the clinical literature, and has been found to be central to the effectiveness of therapy (Del Re, Hovarth, Fluckiger, Symonds, \&Wampold, 2012). In addition to developing a healthy working alliance between the executive coach and leader, trust, warmth and respect for the leader's autonomy has also been found to have considerable implications for success of coaching (Karver, Handelsman, Fields and Bickman, 2006).

Othernon-specific factors such as understanding, encouraging, and listening behaviors of the executive coach havealso been found to be better predictors of coaching effectiveness than specific factors such as coaching methodology (de Haan, Culpin, \& Curd, 2011). Facilitating creative development is a sophisticated process that requires the executive coach to assist the 
leader find a balance between learning skills and stimulating the imagination to explore new ideas (Robinson, 2011). Executive coaches who set developmental plans (a technique used in coaching engagements) also observed competency improvements in leaders compared to those who did not create developmental plans (Smith and Brummel, 2013). An important issue, which is beyond the scope of this paper, is the type of training required for the executive coach, in addition to the specific and non-specific factors mentioned, to successfully navigate the leader through the three stages of the GRM.

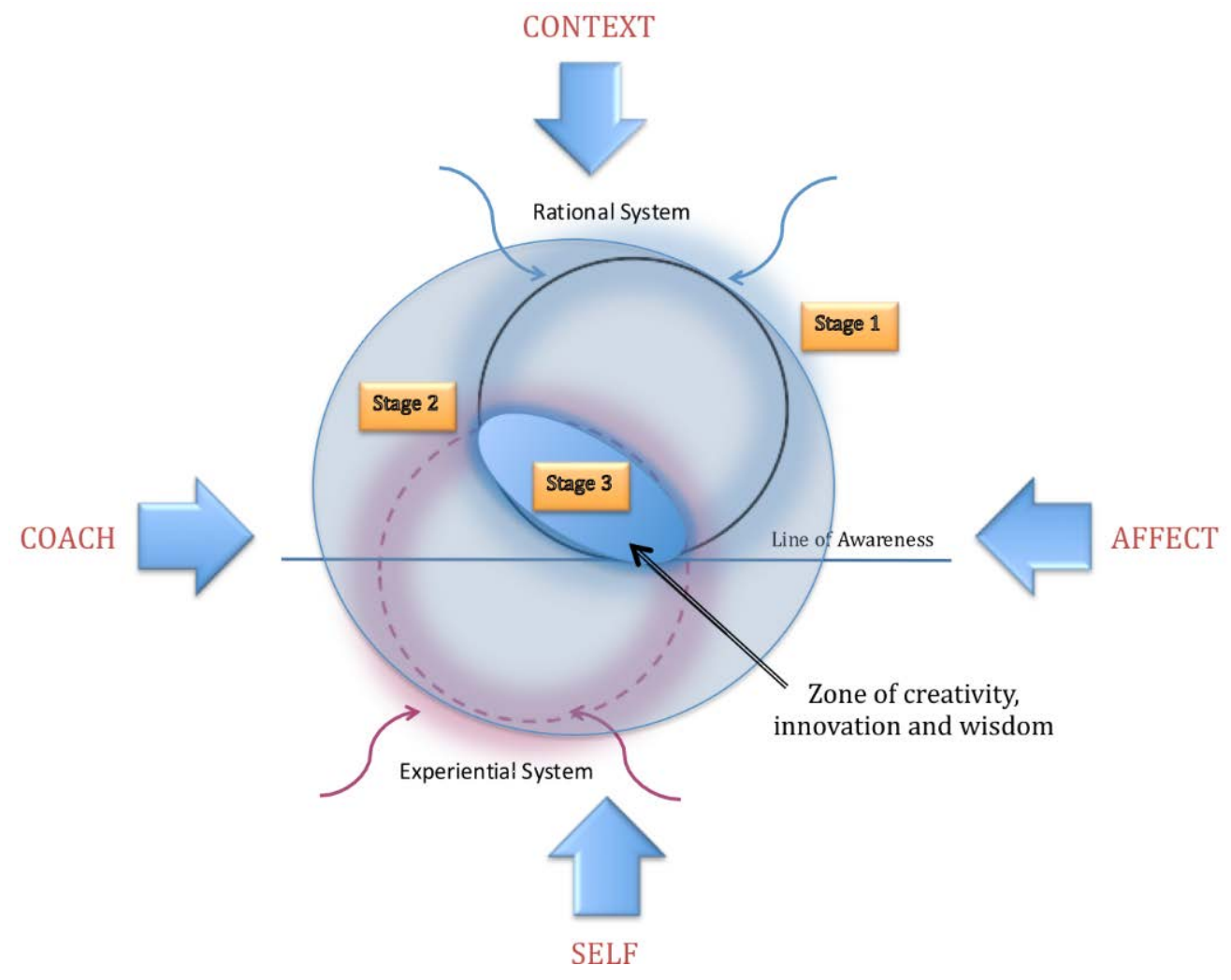

Figure 2. Interaction of factors and stages that influence creativity, innovation and wisdom

\section{Context}

While most reflection appears to take place in the context of problem-solving (Mezirow, 1994), there are many examples where a relaxed, sometimes unexpected context, has generated creativity, innovation and wisdom. The contexts that inspire creativity can include routine activities such as sleeping, walking, having a shower or sitting in the back of a yellow taxi in Manhattan as was the case with Milton Glaser where he scratch the letter "I", followed by a simple outline of a heart, followed by the letters "N" and "Y"(stylized I $\vee$ NY) on the back of an envelope that changed the fortunes of a city and became the world's most imitated logo.

Another example is the work of Professor Graeme Clark who invented the multichannel cochlear implant, also known as the bionic ear. The design conundrum faced by Graeme Clark at the time was to work out how to reach the inner regions of the cochlea responsible for transmitting speech frequencies without causing injury around the tightening spiral of the cochlea. The breakthrough occurred during a family vacation at the beach. He conceptualised using a seashell that had the same spiral shape as the cochlea, or inner ear, and threaded a long grass blade, which was flexible at the tip and gradually increased in stiffness, to represent the electrodes (Scott, 2013).

It seems that the kind of representational change shown by Milton Glaser and Graeme Clark takes place following a period of unconscious processing (van Steenburgh et al.
2012). This is because creativity often taps into areas of the unconscious that are not regulated by conscious thought. Sometimes our best ideas come to mind without thinking consciously about them at all (Robinson, 2011). It is for this reason that in certain relaxed contexts people give priority to the experiential processing to enhance creativity, whereas in more high-pressured work situations they shift towards rational processing (Epstein, 2014).

A sample of questions the executive coach could ask that links creativity and innovation to context includes: "Is the leader feeling comfortable and inspired in the setting?";"Is the context conductive to thinking creatively?"; and “Are the practices; existing knowledge, and past experiences of the leader influenced by the context?" (Phan, 2009).

Affect

Leaders' cognitive and affective states appear to be based on the simple premise that what they do (leaders' practices) depends largely on what they think and feel (Leithwood, 1994). Holding contextual features constant, the greater the affect, the greater the shift in the balance towards the experiential system (Denes-Raj \& Epstein, 1994). CET proposes a single unconscious system in which affect is involved along a dimension that varies from negligible to a major influence (Epstein, 2014).

Without affect there would be no action generated by the experiential system to influence conscious thought and behavior. Affect reinforces automatic learning through emotions and motivates the experiential system by 
interpreting positive and negative events based on past experiences that result in approach or avoidance behaviors. By attending to the leader's feelings and emotions, the implicit beliefs that guide everyday behavior can be interpreted, which may or may be consistent with their conscious beliefs (Epstein, 2014).

The experiential system is considered to be intuitive, spontaneous, emotional, and imagistic part of the brain that allows access to the unconscious (Ketsde Vries, 2013).However most people find it difficult to accept that everyday life is determined not by their conscious intentions and deliberate choice but by mental processes that are put into motion by features of the environment operating outside conscious awareness and guidance (Bargh \& Chantrand, 1999). The experiential system with its intimate association with affect can facilitate the leader's interpersonal relations and creativity (Epstein, 1998b). It is important for leaders to at least acknowledge the role of affect by avoiding becoming unnecessarily emotionally distressed and exercising reasonable emotional control to enhance their creativity and innovation (Epstein, 1998a). Effective executive coaches need to be masters of affect management in order to tune in to their leaders' mood states (Ketsde Vries, 2014).

Commenting on the two types of mental processes, e.g., conscious and unconscious processing and to consciously and wilfully regulate one's own behavior, evaluations, decisions, and emotional states requires considerable effort and is relatively slow. Moreover, it appears that the limited resources that are quickly used up, so conscious self-regulatory acts can only occur sparingly and for a short time. On the other hand, the unconscious or automatic processes are unintended, effortless, very fast, and many of them can operate at any given time making them conducive to thinking in creative ways (Bargh \& Chantrand, 1999).

Self.

Understanding of the self is an important part of the reflection process. Leaders operating with high selfawareness, self-management and social skills tend to have the most effect in developing a positive work climate (Cook-Greuter, 2004). Most assessments look at how leaders differ from each other in terms of personality traits, for example, DISC, Majors PTI, MBTI, MLQ-360, Big Five, and Strengths Finder, however what really matters is how well an individual's style aligns itself with the context and the task at hand(Cook-Greuter, 2004).

An important part of self is self-acceptance, a subscale of emotional coping, and a constructive component of the experiential system, measures the degree to which people have high self-esteem and a generally favourable attitude towards themselves. They can be disappointed in their particular situation, but this does not cause them to evaluate themselves as bad or unworthy people (Epstein, 2001). With self-acceptance and self-tolerance comes acceptance and tolerance of and by others. Self-accepting people tend to be happy people who develop a positive, optimistic outlook without carrying it to the extreme of naïve optimism (Epstein, 1998a).

By developing a good understanding of the self that is associated with high self-esteem and self-acceptance, the leader may spend less time managing their emotions and have more time and room to develop their creativity, innovation and wisdom. This may explain why dreaming in sleep allows us to think through emotional issues in a less rational and defensive way and gain insights that might otherwise remain supressed (Ketsde Vries, 2014). While the context, affect and understanding of the selfhas the potential to enhance creativity, innovation and wisdom, the leader may have minimal understanding about CET information-processing systems and how these systems interact and are influenced by the outer factors found in Stage 1 of the GRM.

There appears to be support for the Stage 1 factors when the context, affect and understanding of the self are applied to the creative and innovative work of Milton Glaser and Graeme Clark. In terms of context, Glaser was not working in his design studio but was waiting in a yellow Manhattan taxi. Similarly Clark was not working in his laboratory but on vocation at the beach with his family. The affect experienced by both Glaser and Clark at the time of their innovation may have been similar, that is, relaxed and reflective. It is also evident that the understanding of the self was high for both Glaser and Clark. Glaser was an accomplished graphic designer who understood the significance of letter shapes, symbols, colour, and design, and at age 34 Clark was the youngest clinical professor of Otolaryngology in Australia. From these two examples there is anecdotal support to suggest that the context, affect, and understanding of self plays an important role in generating important innovations in design. It remains to be established how the executive coach can facilitate the integration of these factors to enhance creativity and innovation.

\section{Stage 2: Inner reflective space}

A critical aspect of leadership may be the degree to which leaders rely on and are influenced by the rational and experiential systems. Would it be preferable for leaders to be high on both rational and experiential processing, low on both or high on one and low on the other? Because CET information-processing systems are independent, leaders could gain information about the interactive influence of the two systems (Epstein, 1998b).

Depending on the situation, being high on either experiential or rational thinking can have its inherent challenges. Leaders who rate themselves high on experiential thinking and low on rational thinking may benefit from therapy so they could learn to be more selfaware and rational by identifying and disputing maladaptive ways of automatically construing events. Notably, such leaders tend to resist such interventions as it may threaten their most fundamental way of experiencing the world, a world that is largely guided by their intuitive impressions. On the other hand, leaders who are high on the rational and low on experiential processing run the risk of: (a) being alienated from the true self, (b) may be lacking in authenticity the ability to relate warmly to others, and (c) not experience joy from their accomplishments (Epstein, 1998b).

As assumed in CET, Shiloh, Salton, and Sharabi, (2002) demonstrated that individual differences interact with contextual cues in producing cognitive bias. Therefore contextual cue, that is, the framing of choice alternatives in negative versus positive terms appears to activate rational and experiential thinking styles differently. Specifically, the results showed that people with high rational/high intuitive ("complementary thinking") and low rational/low intuitive thinking ("poor thinking”) styles 
were the ones most prone to framing effects, that is, people tended to choose more non-risky alternatives under positive framing compared to equally valued options framed negatively. When examining thinking styles separately there was no effect on choice, which suggests that the interaction between the rational and experiential systems is more complex than previously assumed (Shiloh et al., 2002).

From the perspective of CET, the experiential system is intimately associated with affect, mood and emotions (Epstein et al., 1996). The experiential system learns directly from experience and is capable of operating at both low and high levels of functioning. At the lower levels of operation, the experiential system can be seen as a crude system with a tendency to automatically, rapidly, effortlessly and efficiently process information (DenesRaj \& Epstein, 1994; Epstein, 1998b). The experiential system can also process both simple and complex information (Epstein, 1994). Under many circumstances the experiential system solves problems more efficiently than the rational system (Epstein, Denes-Raj, \&Pacini, 1995). At the highest levels, and especially when it interacts with the rational system, it has the capacity to be a source of intuitive wisdom and creativity (Bucci, 1985; Epstein, 1994).

With reference to effective leadership, a Master of Business Administration degree can help provide leaders with analytical skills and theoretical knowledge useful for a business career (Emmott, 2005). However, to become a successful leader in an information-rich, turbulent business world, they also requires maturity, wisdom and the ability to generate intellectual capital (Emmott, 2005; Jacobs, 2005). Effective leaders have the potential to develop these qualities by understanding the influence of the experiential system, how it influences the rational system, and how these in turn are influenced by Stage 1 factors.

\section{Stage 3: Deep reflective space}

Entering deep reflective space(Stage 3) requires the executive coach to work skilfully with the leader to integrate Stage 1 and 2 factors while asking probing questions that promote creativity, innovation and wisdom. Kegan and Lahey's three adult meaning systems appear to be compatible with the three stage GRM and can be mapped onto GRM in terms of the trajectories of the rational and experiential systems that are influenced by Stage 1 factors (see Figure 2). The three adult meaning systems include: socialized mind, self-authoring mind, and the self-transforming mind. According to Kegan and Lahey (2009), the socialized mind is shaped by definitions and expectations of our environment. This suggests that the leader is obtaining meaning from the context as outlined in Stage 1.

The self-authoring mind suggests that the leader is aligned with their belief system, ideology and personal code by being self-directed, taking a stand, setting limits, and regulating boundaries (Kegan \& Lahey, 2009). The self-authoring mind appears to reflect aspects of Stage 2 where the leader is aware of the operation and influence of the rational system that is associated with solving abstract problems and make logical connections (Epstein, 1998b).

The leader with a self-transforming mind can stand back from its own filter and look at it, rather than just looking through it. The self is aligned with the dialectic rather than either pole (Kegan \& Lahey, 2009). The selftransforming mind appears to be similar to Stage 3 where the operation and influence of the rational and experiential systems is considered to be independent, bi-directional, reciprocal chain of reactions (Epstein, 2014). However the self-transforming mind fails to acknowledge the creative, effortless and unconscious properties of the experiential system (Epstein et al., 1996).

The relationship between thinking (rational system) and affect (experiential system) are considered to be at the heart of the creative process with feelings, hunches, subconscious perceptions and intuitions all playing a central role in the creative process (Robinson, 2011). In order to maintain proper functioning of both systems to develop creativity, innovation and wisdom it is essential to promote the continual interaction between intellect and emotions, feeling and reason (Goleman, 1996).

\section{Conclusion}

What is known about CET is that: (a) leaders are continually influenced by the rational and experiential systems; (b) the degree of influence varies from negligible to almost complete dominance, depending on the context, affect and understanding of self, and (c) the overlapping region between the two systems is hypothesised to be the region of creativity, innovation, and wisdom (Epstein 1994; Epstein et al., 1996). Based on this understanding the practical implications for coaching practitioners who work with leaders to enhance their creativity, innovation and wisdom is to:(a) find anexecutive coach with the right skill set; (b) create or find the right context, (c) experience positive affect, including positive thinking, a sub-factor of behavioral coping, and (d) develop a deep understanding of self, including having high intellect that has been found to be associated with the rational system (Epstein \& Meier, 1989).

The emergence of creativity, innovation and wisdom is not considered to be a linear process or a single unitary mental process connected only with the rational system, but rather a result of many different mental processes (Sawyer, 2013) that combined together to draw on the unconscious depths of experiential system. Psychology and neuroscience suggest that the creative process is much less rigid and follows more of a zig-zag sequence of steps including: asking, learning, playing; thinking; fusing; choosing; and making; with each step adding to a collective spark until they give off enough light to reveal a solution (Sawyer, 2013). However, the creative process takes time and is not generally considered to be something that occurs in an instant with a single flash of insight, even though certain insights may occur (Tardif \& Sternberg, 1988).

Sawyer's zig-zag sequence appears compatible with the GRM since it focuses on collecting enough insights from the experiential system that operates at both the conscious and unconscious levels, then waiting until insights rise above the line of awareness (see Figure 1) to be evaluated, and in some cases complemented by the rational system. It is about asking the right questions in deep reflective space (Stage 3) where numerous assumptions and unexpected ideas are drawn to solve the problem? An example of a 
key question could be: "How can the problem be best defined and what would be the best place to solve it?”

Human consciousness is shaped by the ideas, beliefs and values that are derived from our experiences and through the meaning that we derive from them (Robinson, 2011).The experiential system not only processes meaning through lived experiences it also appears to consist of a steady stream of unconscious processing that unexpectedly surfaces above the line of awareness (see Figure 1) in various forms, including biases, that the leaders needs to control to behave relatedly, objectively, and realistically (Epstein, 2003). Material can also surface in the form of creativity, insights and wisdom. These biases and insights sometimes surface between the conscious and unconscious states, typically when people are about to fall asleep or approaching wakefulness.

The GRM suggests that the overlap region between that rational system and constructive elements of the experiential system working in conjunction with Stage 1 and 2 factors may hold the key to creativity, innovation and wisdom. Given that the unconscious processing of the experiential system is associated with creativity and innovation it is the executive coach working with the leader that sets out to unlock the unconscious mind (Davanloo, 1990).

When the executive coach does this well it can stimulate the creative process, encourage psychological risk-taking, help leaders' attain deeper levels of emotional intelligence, and even create a greater sense of realism about what life has to offer (Ketsde Vries, 2013). To activate creative action it is important to obtain relevant information from social networks, avoid pressures from conformity and sustain trust in developing novel and potentially profitable innovations (Ruef, 2002). It is possible that all creative insights are accompanied by unconscious affective responses and the conscious experience of insight directly relates to unconscious processing that precedes it (Kounios, \&Beeman, 2014).

To create effective leadership, it appears that a balance is needed between analytical (rational system), creative, (experiential system), and practical abilities (Sternberg, 2003). Given that most jobs can be completed successfully through a variety of different skill sets, the ultimate success of leadership depends on the ability to capitalize on analytical, creative, and practical strengths (Sternberg, 2003). Sternberg went on to develop a propulsion model that characterizes some of the ways leaders can manifest their creativity.

Successfully drawing on the experiential system that operates at the unconscious level and enabling it to be followed by corrective rational processing has the potential to create new knowledge. For example, the formulation of the world's first successful nuclear chain reaction by Leo Szilard took place during a "burst of defiant creativity” (Lanoutte, 1992). Leo Szilard commented:

The creative scientist has much in common with the artist and the poet. Logical thinking and an analytical ability are necessary attributes to a scientist, but they are far from sufficient for creative work. Those insights in science that have led to a breakthrough were not logically derived from pre-existing knowledge: The creative processes on which the progress of science is based operate on the level of the unconscious. (p. xiii).
In an age of diversity and complexity, it seems essential to transcend the either/or way of thinking that previously juxtaposed the rational/analytic and intuitive modes of thinking, in order to embrace the notion of balance (DavisFloyd \& Arvidson, 1997). Many fields of psychology viewed intelligence as IQ and later viewed other aspects of psychological functioning as distinct from intelligence. Successful intelligence lies at the basis of conventional intelligence (analytical aspect), creativity (creative aspect), and wisdom (practical aspect), because these are the skills that often make the difference between success and failure on the job and life itself (Robinson, 2001; Sternberg, Kaufman, \&Pretz, 2003).

Given that human capability will be the critical variable in the new century, leaders are beginning to ask themselves, "What can I do to make my setting the most fertile ground in the world for the growth of talent, creativity and innovation?” (Kegan \& Lahey, 2009). While the answers may reside with the leader, the GRM suggests that the process needs to move beyond self-reflection to one of interaction between the executive coach and leader to enhance the development of creativity, innovation and wisdom.

\section{References}

[1] Ardelt, M. (2003). Empirical assessment of a three-dimensional wisdom scale. Research and Aging, 25, 275-324.

[2] Bandura, A. (1986). Social foundations of thought and action: A social cognitive theory. Eaglewood Cliffs, NJ: Prentice Hall.

[3] Bargh, J. A., \& Chartrand, T. L. (1999). The unbearable automaticity of being. American Psychologist, 54, 462-479.

[4] Bass, B. M. (1985). Leadership and performance beyond expectations. New York: The Free Press.

[5] Bourner, T. (2003). Assessing reflective learning. Education and Training, 45, 267-272.

[6] Buber, M. (1958). I and Thou (R. \& G. Trans.). New York, NY: Charles Scribner's Sons.

[7] Cerni, T., Curtis, G.J., \& Colmar, S.H. (2008). Informationprocessing and leadership styles: Constructive thinking and transformational leadership, Journal of Leadership Studies, 2, 6073.

[8] Cerni, T., Curtis, G.J. \& Colmar, S.H. (2010a). Executive coaching can enhance transformational leadership. International Coaching Psychology Review, 5, 83-87.

[9] Cerni, T., Curtis, G. J., \& Colmar, S. H. (2010b). Increasing transformational leadership by developing leaders' informationprocessing systems. Journal of Leadership Studies, 4, 51-65.

[10] Cerni, T., Curtis, G.J. \& Colmar, S.H. (2012). Cognitiveexperiential self theory and conflict-handling styles: Rational and constructive experiential systems are related to the integrating and compromising conflict-handling styles. International Journal of Conflict Management, 23, 362-381.

[11] Cerni, T., Curtis, G.J. \& Colmar, S.H. (2014). The cognitive information-processing systems of leaders and their relation to student learning outcomes. Journal of School Leadership, 24, $287-$ 310.

[12] Cerni, T., Curtis, G. J., \& Colmar, S. H. (2015). Cognitive leadership model: How leaders' information-processing systems can influence leadership styles, conflict management and organizational outcomes. Journal of Leadership Studies, 8(3), 2639.

[13] Clayton, P., \& Ash, S. (2005). Reflection as a key component in faculty development. On the Horizon, 13, 161-169.

[14] Cook-Greuter, S.R. (2004). Making a case for a developmental perspective. Industrial and Commercial Training, 36, 275-281.

[15] Curtis, G. J., \& Lee, M. H. W. (2013). Connecting cognitiveexperiential self theory's information-processing styles with organizational influencing tactics: Rational thinkers are rational persuaders. Australasian Journal of Organizational Psychology, 6(e2), 1-11. 
[16] Davanloo, H. (1990). Unlocking the unconscious: Selected papers of Habib Davanloo. New York, NY: Wiley.

[17] Davis-Floyd, R., \& Arvidson, S. P. (1997). Intuition-the inside story interdisciplinary perspective. New York: Routlidge.

[18] De Haan, E., Culpin, V., \& Curd, J. (2011). Executive coaching in practice: What determines helpfulness for clients of coaching? Personnel Review, 40, 24-44.

[19] Del Re, A.C., Hovarth, A.O., Fluckiger, C., Symonds, D., \& Wampold, B.E. (2012). Therapist effects in the therapeutic alliance-outcome relationship: A restricted-maximum likelihood meta-analysis. Clinical Psychology Review, 32, 642-649.

[20] Denes-Raj, V., \& Epstein, S. (1994). Conflict between intuitive and rational processing: when people behave against their better judgment. Journal of Personality and Social Psychology, 66, 819829.

[21] Dubinsky, A. J., Yammarino, F. J., \& Jolson, M. A. (1995). An examination of linkages between personal characteristics and dimensions of transformational leadership. Journal of Business and Psychology, 9, 315-334.

[22] Elliott, R. (2010). Religious beliefs, spirituality and coaching for leadership development, Journal of Spirituality, Leadership and Management, 4, 86-104.

[23] Epstein, S. (1994). Integration of the cognitive and the psychodynamic unconscious. American Psychologist, 49, 709-724.

[24] Epstein, S. (1998a). Constructive thinking: the key to emotional intelligence. London: Praeger.

[25] Epstein, S. (1998b). Cognitive-experiential self theory: A dualprocess personality theory with implications for diagnosis and psychotherapy. In R. F. Bornstein \& J. M. Masling (Eds.), Empirical perspectives on the psychoanalytic unconscious (pp. 99140). Washington, DC: American Psychological Association.

[26] Epstein, S. (2000). The rationality debate from the perspective of cognitive-experiential self theory. Behavioral and Brain Science, 23, 671.

[27] Epstein, S. (2001). Constructive Thinking Inventory: Professional Manual. Lutz, Florida: Psychological Assessment Resources, Inc.

[28] Epstein, S. (2003). Cognitive-experiential self theory of personality. In T. Millon \& M. J. Lerner (Eds.), Comprehensive handbook of psychology: Personality and social psychology (Vol. 5). Hoboken, NJ: Wiley \& Sons.

[29] Epstein, S. (2006). Intuition from the perspective of Cognitiveexperiential Self-theory. Unpublished manuscript: University of Massachusetts at Amherst.

[30] Epstein, S. (2014). Cognitive-Experiential Theory: An Integrative Theory of Personality. New York, NY: Oxford University Press.

[31] Epstein, S., \& Meier, P. (1989). Constructive thinking: A broad coping variable with specific components. Journal of Personality and Social Psychology, 57, 332-350.

[32] Epstein, S., Pacini, R., Denes-Raj, V., \& Heier, H. (1996). Individual differences in intuitive-experiential and analyticalrational thinking styles. Journal of Personality and Social Psychology, 71, 390-405.

[33] Fullan, M. (2001). Leading in a culture of change. San Francisco: Jossey-Bass.

[34] Goleman, D. (1996). Emotional intelligence. Bloomsbury, London.

[35] Goldman, E., Wesner, M., \& Karnachanomai, O. (2013). Reciprocal peer coaching: A critical contributor to implementing individual leadership plans. Human Resource Development Quarterly, 24, 63-87.

[36] Gray, D.E. (2006). Executive coaching: Towards a dynamic alliance of psychotherapy and transformative learning process. Management Learning, 37, 475-497.

[37] Hall, R. J., \& Lord, R. G. (1995). Multi level information processing explanations of followers' leadership perceptions. Leadership Quarterly, 6, 265-287.

[38] Handley, S. J., Newstead, S. E., \& Wright, H. (2000). Rational and experiential thinking: A study of the REI. In R. J. Riding \& S. G. Rayner (Eds.), International perspectives on individual differences (Vol. 1. Cognition styles): [SEN].

[39] Hollander, E. P. (2009). Inclusive leadership: The essential leader-follower relationship. New York, NY: Routledge.

[40] Houghton, J.D., Wu, J., Godwin, J.L., Neck, C.P., \& Manz, C.C. (2012). Effective stress management: A model of emotional intelligence, self-leadership, and student stress coping. Journal of Management Education, 36, 220-238.

[41] Humphreys, J. H., \& Zettel, M. C. (2002). Transformational leader self-perception and objective sales performance: The potential moderating effects of behavioral coping ability. International Business \& Economics Research Journal, 1, 9-23.

[42] Karver, M.S., Handelsman, J.B., Fields, S, \& Bickman, L. (2006). Meta-analysis of therapeutic relationship variables in youth and family therapy: The evidence for different relationship variables in the child and adolescent treatment outcome literature. Clinical Psychology Review, 26, 50-65.

[43] Kegan, R., \& Lahey, L.L. (2009). Immunity to change: How to overcome it and unlock the potential in yourself and your organization. Boston, MA: Harvard Business Press.

[44] Kets de Vries, M.F.R. (2014). Dream journeys: A new territory for executive coaching. Consulting Psychology Journal: Practice and Research, 66, 77-92.

[45] Kets de Vries, M.F.R. (2013). Coaching’s good hour': Creative tipping points. Coaching: An International Journal of Theory, Research and Practice, 6, 152-175.

[46] Kolb, D. (1983). Experiential learning: Experience as the source of learning an development. Eaglewood Cliffs, NJ: Prentice-Hall.

[47] Kounios, J., \& Beeman, M. (2014). The cognitive science of insight. Annual Review of Psychology, 65, 71-93.

[48] Lane, D.A., \& Corrie, S. (2009). Does coaching psychology need the concept of formulation. International Coaching Psychology Review, 4, 195-208.

[49] Lanoutte, W. (1992). Genius in the shadows: A biography of Leo Szilard. New York: Charles Scribner's Sons.

[50] Leithwood, K. (1994). Leadership for school restructuring. Educational Administration Quarterly, 30, 498-518.

[51] Leung, D.Y.P., \& Kember, D. (2003). The relationship between approaches to learning and reflection upon practice. Educational Psychology, 23, 61-71.

[52] McKenna, B., Rooney, D., \& Boal, K.B. (2009). Wisdom principles as a meta-theoretical basis for evaluating leadership. The Leadership Quarterly, 20, 177-190.

[53] Mezirow, J. (1998). On critical reflection. Adult Education Quarterly, 48, 185-198.

[54] Norris, P., \& Epstein, S. (2011). An experiential thinking style: Its facets and relations with objective and subjective criterion measures. Journal of Personality, 79, 1043-1079.

[55] Ollila, S. (2002). Project Management - Multidimensional Leadership. Gothenburgh: Chalmers University of Technology.

[56] Pacini, R., \& Epstein, S. (1999). The relation of rational and experiential information processing styles to personality, basic beliefs, and the ratio-bias phenomenon. Journal of Personality and Social Psychology, 76, 972-987.

[57] Phan, H.P. (2009). Exploring students' reflective thinking practice, deep processing strategies, effort, and achievement goal orientations. Educational Psychology, 29, 297-313.

[58] Prochaska, J.O., Velicier, W.F., Rorri, J.S., \& Goldstein, M.G. (1994(. Stages of change and decisional balance for 12 problem behaviors. Health Psychology, 13, 39-46.

[59] Robinson, K. (2001). Mind the gap: The creative conundrum. Education, 43, 41-45.

[60] Robinson, R. (2011). Out of our minds: Learning to be creative. West Sussex, UK: Capstone Publishing Ltd.

[61] Ruef, M (2002). Strong ties, weak ties and islands: Structural and cultural predictors of organizational innovation. Industrial and Corporate Change, 11, 427-449.

[62] Sawyer, K. (2013). Zig zag: The surprising path to greater creativity. Jossey-Bass: San Francisco, CA.

[63] Schon, D.A. (1987). Educating the reflective practitioners. San Francisco, CA: Jossey-Brass.

[64] Scott, R. (2013, October, 10). Inventor of bionic ear wins prestigious award and inspires new filed of endeavour. The Age. This story was fund at: http://www.theage.com.au/national/education/voice/inventor-ofbionic-ear-wins-prestigious-award-and-inspires-new-field-ofendeavour-20131008-2v5bd.html.

[65] Shiloh, S., Salton, E., \& Sharabi, D. (2002). Individual differences in rational and intuitive thinking styles as predictors of heuristics responses and framing effects. Personality and Individual Differences, 32, 415-429.

[66] Smith, I.M., \& Brummel, B.J. (2013). Investigating the role of the active ingredients in executive coaching. Coaching: An International Journal of Theory, Research and Practice, 6, 57-71.

[67] Sternberg, R. J. (1998). A balance theory of wisdom. Review of General Psychology, 2, 347-365. 
[68] Sternberg, R. J. (2003). A broad view of intelligence: The theory of successful intelligence. Consulting Psychology Journal: Practice and Research, 55, 139-154.

[69] Sternberg, R. J., Kaufman, J. C., \& Pretz, J. E. (2003). A propulsion model of creative leadership. The Leadership Quarterly, 14, 455-473.

[70] Theeboom, T., Beersma, B., \& van Vianen, A.E. (2014). Does coaching work? A meta-analysis of the effects of coaching on individual level outcomes in an organizational context. The Journal of Positive Psychology, 9, 1-18.

[71] Tradif, T.Z., \& Sternberg, R.J. (1988). What do we know about creativity? In R.J. Sternberg (Ed.), The nature of creativity (pp. 429-440). New York, NY: Cambridge University Press.

[72] Thompson, D. A., Grahek, M., Phillips, R. E. \& Fay, C. L. (2010) The search for worthy leadership. Consulting Psychology Journal: Practice and Research, 60, 366-382.

[73] van Steenburgh, J., Fleck, J.I., Beeman, M., \& Kounios, J. (2012) Insight. In K. Holyoak \& R. Morrison (Eds). The Oxford
Handbook of Thinking and Reasoning (pp. 475-91. New York: Oxford University Press.

[74] Vancouver, J.B., \& Putka, D.J. (2000). Analyzing goal-striving processes and a test of the generalizability of perceptual control theory. Organozational Behavior and Human Decision Processes, 82, 334-362.

[75] Webster, J.D. (2003). An exploratory analysis of a self-assessed wosdom scale. Journal of Adult Development, 10, 13-22.

[76] Welch, D., Grossaint, K., Reid, K., \& Walker, C. (2014). Strengths-based leadership development: Insights from expert coaches. Coaching Psychology Journal: Practice and Research, 66, 20-37.

[77] Woerkom, M. (2003). Critical reflection at work: Bridging individual and organizational learning. $\mathrm{PhD}$ thesis. Twente University, Enschede/Print Partners, Ipskamp. 